\title{
CHOROIDAL TUBERCLES IN ISOLATED TUBERCULOUS MENINGITIS
}

\author{
Tharun Tom Oommen ${ }^{1}$, Parvathi Mallesh2, Madhumathi Ramaiah³, Asif Ali Thayyil4, Lakshmi Narayanagowda ${ }^{5}$
}

${ }_{1}^{1}$ Post Graduate Student, Department of General Medicine, Bangalore Medical College and Research Institute, Bangalore. ${ }^{2}$ Senior Resident, Department of General Medicine, Bangalore Medical College and Research Institute, Bangalore. ${ }_{3}^{3}$ Associate Professor, Department of General Medicine, Bangalore Medical College and Research Institute, Bangalore. ${ }_{4}^{4}$ Post Graduate Student, Department of General Medicine, Bangalore Medical College and Research Institute, Bangalore. 5 Post Graduate Student, Department of General Medicine, Bangalore Medical College and Research Institute, Bangalore.

\section{ABSTRACT}

Choroidal tubercles are the most common manifestation of intraocular tuberculosis and results from the haematogenous spread of mycobacteria in miliary tuberculosis. However, its presence without the evidence of miliary tuberculosis is a rare entity. We present a case of isolated tuberculous meningitis with choroidal tubercles, who had no features of miliary tuberculosis.

\section{KEYWORDS}

Choroidal Tubercles, Tuberculous Meningitis, Miliary Tuberculosis.

HOW TO CITE THIS ARTICLE: Oommen TT, Mallesh P, Ramaiah M, et al. Choroidal tubercles in isolated tuberculous meningitis. J. Evolution Med. Dent. Sci. 2016;5(33):1858-1859, DOI: 10.14260/jemds/2016/437

\section{INTRODUCTION}

Choroidal tuberculosis manifests as choroidal tubercles, tuberculomas and abscess. Serpiginous-like choroiditis has been described. An upsurge of mycobacterial infections has occurred in the era of AIDS. The patient may present with decreased vision from macular involvement. Posterior segment examination will show choroidal tubercles. These tubercles usually are less than five in number, may be unilateral or bilateral, greyish white-to-yellow in colour with indistinct borders. On fluorescein angiography, they are hypofluorescent during the dye transit phase and hyperfluorescent during the late phase. On healing, the tubercles result in pigmented and atrophic scars.

Miliary tuberculosis accounts for $2 \%$ of all forms of active tuberculosis. 1 TB meningitis has been described in 10 to 30 percent of adult patients with miliary tuberculosis, conversely about one-third patients presenting with TB meningitis have underlying miliary tuberculosis. Acute or classical miliary tuberculosis maybe associated with an acute or subclinical febrile illness, but often in adults the onset is insidious with gradual development of malaise, anorexia, weight loss and fever. Cough, breathlessness, haemoptysis and night sweats are less common. Headache as a feature suggests associated tuberculous meningitis. Apart from fever there may be no physical signs in particular; chest is frequently normal on auscultation, although crepitations may develop in late stages. Hepatosplenomegaly, nuchal rigidity, lymphadenopathy and splenomegaly may be present. ${ }^{2}$

Choroidal tubercles are found in $90 \%$ of children and to a lesser extent in adults. Miliary lesions of the skin are occasionally seen and may take the form of macules, papules, vesicles or purpuric lesions. Cryptic miliary disease is increasingly being seen in elderly. ${ }^{3}$

Financial or Other, Competing Interest: None.

Submission 05-03-2016, Peer Review 31-03-2016,

Acceptance 07-04-2016, Published 25-04-2016.

Corresponding Author:

Dr. Tharun Tom Oommen,

12 UTC Quarters,

97 Nandidurga Road,

Benson Town Post,

Bangalore-46,

E-mail: tharuntom@gmail.com

DOI: $10.14260 /$ jemds $/ 2016 / 437$
Where it may be difficult to diagnose since the X-ray may be normal, choroidal tubercles are absent and the tuberculin test may be negative.

\section{CASE REPORT}

A nineteen year old girl presented with history of fever, headache and decreased vision of the right eye of three weeks' duration. On examination she was conscious, oriented but irritable. Visual acuity of the right eye was 6/24. Fundus examination revealed multiple yellow subretinal tubercles. No other focal deficits were present except for signs of meningeal irritation. However, there was no lymphadenopathy, skin lesions, consolidation or hepatosplenomegaly.

Investigations done to evaluate fever are as follows. Hb12.6, TC-6780, platelet count-340000, ESR-86 mm. RFT, LFT and serum electrolytes were within normal limits. CT brain was essentially normal. CSF analysis showed protein of 134 $\mathrm{mg} / \mathrm{dL}$, Sugar $30 \mathrm{mg} / \mathrm{dL}$, ADA-54 IU/mL, cell count of 90 cell with $10 \%$ neutrophils and $90 \%$ lymphocytes. Sputum AFB and HIV were negative. Chest X-ray, USG Abdomen and CT Thorax were normal. Patient was subjected to Fundus Fluorescent Angiography.

The tubercles showed an early hypofluorescence with the appearance of the dye in the late phase. These findings were consistent with choroidal tubercles. She was started on anti-tubercular therapy and steroids to which she responded and there was significant improvement in vision.

\section{DISCUSSION}

Miliary tuberculosis is produced by acute dissemination of tubercles via the bloodstream. It is more common in infants and young children. Although, the overt case is easily diagnosed, cryptic forms are usually missed. These cryptic forms are more common in older people. The cryptic form is also conspicuous by the absence of choroidal tubercles and meningitis. As our patient is young and has both choroid tubercles and tuberculous meningitis, it is unlikely to be a case of cryptic tuberculosis. 


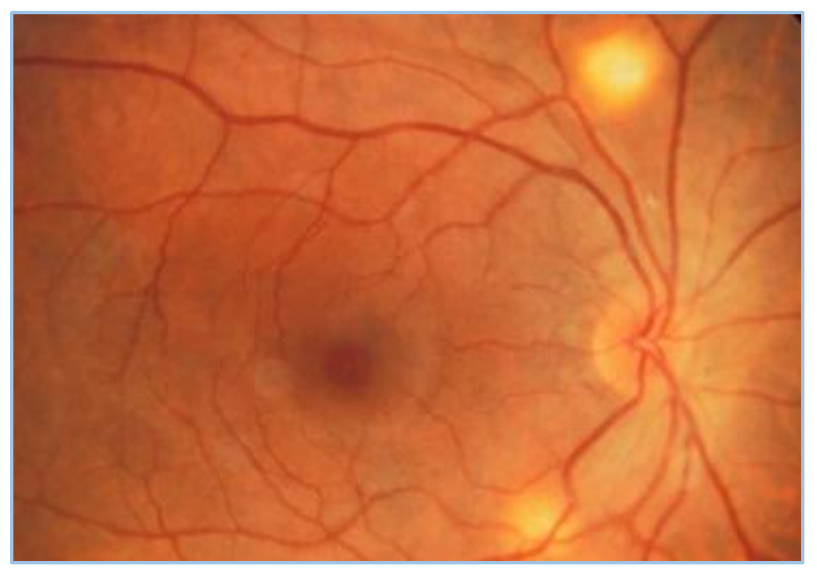

Choroidal Tubercles. Yellowish Discrete Lesions

The classical form is usually easy to diagnose because of the typical X-ray appearances, which are only absent in the early stages. ${ }^{4}$ However, at this stage high resolution CT scan usually picks up the miliary lesions. As in our case there was no evidence of miliary seeding in HRCT, it is unlikely to be miliary tuberculosis also. Infrequently choroidal tubercles may be associated with pulmonary or extrapulmonary tuberculosis. ${ }^{5}$ in our case tuberculous meningitis.

\section{CONCLUSION}

Choroidal tubercles thought to be pathognomonic of miliary tuberculosis may occur in isolated tuberculous meningitis.

\section{REFERENCES}

1. Sutherland I. The ten-year incidence of clinical tuberculosis following conversion in 2550 individuals aged 14-19 years. TSRU Progress Report (KNCV, POB 146, The Hague), 1968.

2. Biehl JP. Miliarytuberculosis: a review of sixty-eight adult patients admitted to a municipal general hospital. Am Rev Tuberc 1958;77(4):605-22.

3. Sime PJ, Chivers ER, Leitch AG. Deaths in notified cases of tuberculosis in Edinburgh: a comparison between 19841992 and 1954-1967. Respir Med 1994;88(8):609-11.

4. Long R, O'Connor R, Palayew M, et al. Disseminated tuberculosis with and without a miliary pattern on chest radiograph: a clinical-pathologic-radiologic correlation. Int J Tuberc Lung Dis 1997;1(1):52-8.

5. Tejada P, Mendez MJ, Negreira S. Choroid tubercles in tuberculous meningitis. Int Ophthalmol 1994;18(2):1158. 